\title{
Role of Advanced Glycation End Products and Vascular Endothelial Growth Factor in Pathophysiology of Diabetic Retinopathy
}

\author{
Marwa A. Ahmed, Omar M.Aly ${ }^{*}$, Ehab I.Wasfy ${ }^{*}$ and Salwa I.Wasfy \\ Physiology and Ophthalmology Departments", \\ Faculty of Medicine, Assiut University
}

\begin{abstract}
Background: The hyperglycemic state occurring in diabetes mellitus is responsible for formation and accumulation of advanced glycation end products (AGEs) that participate with their receptors, receptor for advanced glycation end products (RAGE ) in the pathogenesis of vascular complications of diabetes mellitus. Intraocular vascular endothelial growth factor (VEGF) levels have been studied in animal models and human vitreous fluid, where the levels are found to be high in patients with active intraocular neovascularization. Objective: To investigate the levels of AGEs, soluble form of RAGE (sRAGE),VEGF and total antioxidants (TAO) in both vitreous and blood of diabetic patients with and without diabetic retinopathy. Study Design: Blood and vitreous samples were collected from 30 diabetic patients, 15 with proliferative diabetic retinopathy (PDR), 15 without retinopathy, and 15 non diabetic control subjects. ELISA technique was used for measuring vitreous and blood levels of AGE, sRAGE, VEGF and TAO. Results: AGEs, sRAGE and VEGF levels in blood were significantly higher in all diabetic groups compared to controls and in PDR patients compared to diabetic group. There were positive correlations between serum AGEs, sRAGE and VEGF levels in both diabetic groups. Vitreous levels of AGEs and $V E G F$ were significantly increased in all diabetic groups compared to controls and in PDR group compared to diabetic group. Also there were significant correlations between these levels in both PDR and diabetic groups. Serum and vitreous TAO levels were decreased in patients with diabetes compared to controls and in patients with PDR compared to diabetics without retinopathy. Furthermore, Serum TAO levels were inversely correlated with serum levels of $A G E s$, sRAGE and VEGF in all diabetic patients. TAO levels in vitreous were inversely correlated with vitreous levels of AGEs, and VEGF in all diabetic patients. Conclusion: These findings suggest that the interaction of advanced glycation end products (AGEs), with their cellular receptor (RAGE) and oxidative stress is implicated in the pathogenesis of diabetic vascular complications through stimulation of VEGF.
\end{abstract}




\section{INTRODUCTION}

Diabetic retinopathy is a common and potentially devastating microvascular complication in diabetes and is a leading cause of acquired blindness among the people of occupational age. Chronic hyperglycemia is a major initiator of diabetic retinopathy ${ }^{(\mathbf{1})}$. Among various pathways implicated in the pathogenesis of diabetic retinopathy, the process of formation and accumulation of advanced glycation end products (AGEs) and their mode of action are most compatible with the hyperglycemic theory ${ }^{(2)}$.

Hyperglycaemia leads to nonenzymatic glycation of intracellular and extracellular proteins with the formation of AGEs. The formation and accumulation of AGE is known to progress during normal ageing, and at an extremely accelerated rate in diabetes mellitus ${ }^{(\mathbf{3})}$.

The best-characterised receptor for AGEs is the receptor for AGEs (RAGE, also known as AGE-specific receptor [AGER]). RAGE belongs to the immunoglobulin superfamily of cell-surface molecules ${ }^{(4)}$. The role of RAGE in diabetic vasculopathy has been investigated in animal and human studies $^{(\mathbf{5})}$. RAGE has a circulating secretory receptor form, soluble RAGE (sRAGE) which can be measured in peripheral blood, and result from the expression of a RAGE gene $^{(6)}$. It consists of only the extracellular ligand binding domain and lacking the cytosolic and transmembrane domains. Due to these characteristics, the sRAGE represents a naturally occurring competitive inhibitor of the signaling pathways induced by the interaction of AGEs with its cellular receptor; by functioning as a decoy, sRAGE may contribute to the removal/neutralization of circulating RAGE-ligands ${ }^{(7)}$.

Vascular endothelial growth factor(VEGF) is responsible for the growth of new blood vessels by stimulating the endothelial cells which form the walls of the vessels and transport nutrients and oxygen to the tissues. In normal retina,VEGF expression is limited to vessel walls and the retinal pigment epithelium ${ }^{(8)}$. Angiogenesis (or neovascularization) refers to the development of new vessels from a preexisting vascular bed. During embryonic development and the menstrual cycle, angiogenesis is a physiological process. In the adult, the vascular endothelium is remarkably quiescent, with a turnover time of several years. The retinal vascular endothelium is even more quiescent as its turnover time is 25 years $^{(9)}$.

Angiogenesis is the major feature in the pathogenesis of proliferative diabetic retinopathy (PDR), in which the retinal neovascularization has a catastrophic effect on vision by causing vitreous haemorrahage, retinal detachment with formation of a fibrovascular membrane and eventual blindness ${ }^{(10)}$.

Oxidative tissue and organ damage may play roles in diabetes and its complications (11). Specifically, in diabetic retinopathy, both the genesis and the advanced stage of proliferative diabetic retinopathy (PDR) have been hypothesized to be a result of increased oxidative species or to be associated with ischemia - 
reperfusion injury at the boundaries of perfused and non perfused retina, which leads to both increcresed oxidative species and neovascularization ${ }^{(\mathbf{1 2})}$. Diabetes results in increased oxidative stress, and elevated oxidative stress plays an important role in the pathogenesis of diabetic complications ${ }^{[11]}$. Increased oxidative stress in diabetes is postulated to promote the development of neuropathy ${ }^{(\mathbf{1 4})}$, nephropathy ${ }^{(\mathbf{1 5})}$, myocardial injury ${ }^{(\mathbf{1 6})}$, and retinopathy ${ }^{(17)}$.

The aim To evaluate the levels of AGEs, sRAGE ,VEGF and total antioxidants in both vitreous and blood of diabetic patients with and without diabetic retinopathy. The motivation behind this study was to determine their possible role in pathophysiology of diabetic retinopathy which may be needed for prophylactic and therapeutic purposes.

\section{PATIENTS \& METHODS}

This study included 30 persons (14 men \& 16 women) with ages ranged from 51-57 years. It was carried in both Ophthalmology and Physiology Departments, Faculty of medicine, Assiut University from January 2007 until October 2008. The protocol was approved by the Faculty of Medicine, Assiut University Human Study Ethics Committee, and informed consent was obtained from each patient before the collection of samples. Diabetic patients were classified into 2 groups:

1-PDR group: included 15 diabetic patients (6 type I \& 9 type II) with proliferative diabetic retinopathy.
2-Diabetic group: included 15 diabetic patients (7type I \&8type II) without diabetic retinopathy with other vitreo retinal conditions as macular hole $(\mathrm{n}=10)$ and epiretinal membrane $(\mathrm{n}=5)$.

Control group: included 15 non diabetic patients with other conditions requiring vitrectomy, as macular hole $(\mathrm{n}=9)$ and epiretinal membrane $(\mathrm{n}=6)$.

Full ophthalmological examination and medical history was taken for each subject including:

1. Intraocular pressure measurement by applanation tonometry.

2. Slit lamp examination to determine anterior chamber depth and presence of iris neovascularization . Indirect ophthalmoscopy and biomicroscopy to evaluate the grade of vitreous proliferation and determine the presence or absence of macular oedema.

Exclusion criteria: Any patient with local eye disease such as, cataract, glaucoma or uveitis was excluded from the study. Also any patient with serum creatinine $>1.2 \mathrm{mg} / \mathrm{dl}$ or urinary albumin excretion $>150$ $\mathrm{mg} / 24 \mathrm{hrs}$ was not included in this study.

Vitreous collection: Vitreous samples $(1-2 \mathrm{ml})$ were obtained at the onset of vitrectomy by aspiration into a syringe attached to the vitreous cutter before starting intravitreal infusion of a balanced salt solution. The vitreous samples were transferred to a tube, placed immediately on ice, and were frozen at $-70^{\circ} \mathrm{C}$ until assayed.

Plasma and Serum collection:

Blood samples (4ml) were collected simultaneously with the vitrectomy from healthy controls and patients, the samples were taken from 
an anticubital vien and were transferred to chilled sterile disposable tubes. $1 \mathrm{ml}$ was heparinized and separated as plasma and the rest was separated as serum after centrifugation at 3,000 r.p.m. for $20 \mathrm{~min}$. Plasma and serum were stored immediately at $-70^{\circ} \mathrm{C}$ until assay.

\section{Laboratory assays:}

Assay kits for estimation by Enzyme -linked immunosorbent assays (ELISA) with monoclonal antibodies against each substance were used following the instructions supplied with each kit for measuring of:

VEGF: Levels of VEGF $(\mathrm{pg} / \mathrm{ml})$ in both vitreous and plasma samples were measured using kits supplied from (Koma Biotech Inc, Soeul, Korea) AGE: AGE was measured with a kit supplied from (Sigma, St Louis, MO,USA). sRAGE: Serum sRAGE levels were determined using kits of (R\&D systems, Minneapolis, MN, USA).Total antioxidant levels: Total antioxidant levels were also analyzed with a available ELISA kit (Calbiochem, La Jolla, CA, USA) .

\section{Statistical Analysis:}

All values were expressed as mean \pm SE for all parameters. These data were analysed by using GraphPad Prism data analysis program (GraphPad Software, Inc., San Diego, CA, USA). Examination of significance was performed with Student Newman-Kleus t-test for unpaired data. For multiple comparisons, one-way analysis of variance (ONE- WAY- ANOVA) test followed with at least significant difference was used. Correlations were assessed using Spearman's nonparametric correlation coefficient $p$
(11) .Levels of significance (P) was considered as follow: (1) $\mathrm{P}>0.05$, not significant; (2) $\mathrm{P} \leq 0.05$, significant (3) $\mathrm{P} \leq 0.001$, highly significant (18).

\section{RESULTS}

The clinical characteristics of the controls, diabetic and PDR are shown in Table 1. The serum blood sugar levels for diabetic patients were significantly higher than those of control subjects $(p<0.001)$ and in PDR group than in diabetic group $(\mathrm{p}<0.001)$.

The plasma levels of VEGF, serum levels of AGEs and sRAGE were significantly higher in all diabetic patients than control subjects ( $p>0.001$, respectively). Also plasma levels of VEGF, serum levels of AGEs and sRAGE in PDR group were significantly elevated compared with diabetic group $(\mathrm{p}>0.001$, respectively).On the other hand, the serum levels of TAO were significantly decreased in all diabetic groups compared to controls (P $<0.0001)$. Also serum levels of TAO in PDR patients were significantly decreased compared to diabetic group $(\mathrm{p}>0.001)$. Data are presented in Table (2).

The vitreous levels of both AGE and VEGF were significantly higher in all diabetic patients than in control subjects ( $p>0.001$, respectively).Also these levels were significantly increased in PDR group than diabetic group ( $p>0.001$, respectively).

Total antioxidant levels in the vitreous was decreased in diabetic patients compared with control subjects $(p<0.001)$. Vitreous levels of TAO were decreased in PDR group 
than diabetic groups $(\mathrm{p}<0.001)$, Data are shown in Table (3).

Figure 1A shows that there were positive correlations between serum levels of AGE and both plasma levels of VEGF and serum levels of sRAGE in all diabetic patients including diabetic and PDR groups $(\mathrm{r}=0.84, \mathrm{r}=$ 0.42 ,respectively, $\mathrm{p}<0.001)$. Positive correlations between plasma levels of VEGF and serum levels of sRAGE in all diabetic patients were found $(\mathrm{r}=$ $0.98, \mathrm{p}<0001)$.

Inverse correlations between serum levels of TAO and blood levels of AGE, VEGF and sRAGE in all diabetic patients are presented in Figure $1 \mathrm{C}(\mathrm{r}=0 .-93, \mathrm{r}=-0.88, \mathrm{r}=$ $0.84, \mathrm{p}<0001$,respectively).

There was a significant correlation between the vitreous levels of AGE and VEGF in all diabetic patients of both diabetic and PDR groups $(\mathrm{r}=0.0 .98, \mathrm{p}<0.0001) \quad$ Table (4).

Furthermore, as shown in table (4) total antioxidant levels in vitreous in both groups were nversely correlated with the vitreous AGE and VEGF levels $(r=-0 .-0.92, r=-$ 0.87 respectively, $\mathrm{p}<0.001$ ).

There were no significant correlations between blood levels of AGE, VEGF, sRAGE and TAO with vitreous levels of studied parameters.

There were no significant correlations between blood and vitreous levels of any of studied parameters with serum levels of glucose in all studied groups.

Table (1): Characteristics of controls, diabetic and PDR groups included in this study

\begin{tabular}{|l|l|l|l|}
\hline Parameter & Control & Diabetic & PDR \\
\hline Number & 15 & 15 & 15 \\
Male/female & $5 / 10$ & $8 / 7$ & $6 / 9$ \\
Age (years) (mean \pm SE) & $51 \pm 6.6$ & $54 \pm 7.7$ & $55 \pm 7.5$ \\
Duration of Diabetes (mean \pm SE) & -- & $11.88 \pm 2.1$ & $11.21 \pm 1.88$ \\
Serum glucose (mg/dl) & $90.7 \pm 0.5$ & $183.4 \pm 1.3^{\text {a }}$ & $229.5 \pm 0.6^{\text {a,b }}$ \\
(TypeI / type II) & & $(7 / 8)$ & $(6 / 9)$ \\
\hline
\end{tabular}

a: $P<0.001$ as compared to the control group

$b: P<0.001$ as compared to the diabetic group 
Table (2): Blood levels of different parameters in all studied groups

\begin{tabular}{|l|l|l|l|}
\hline & Control & Diabetic & PDR \\
\hline VEGF (pg/ml) & $20.20 \pm 0.24$ & $28.51 \pm 0.49^{\mathrm{a}}$ & $52.75 \pm 1.23^{\mathrm{a} b}$ \\
& & & \\
\hline AGE $(\mathrm{unit} / \mathrm{ml})$ & $4.095 \pm 0.10$ & $4.583 \pm 0.081^{\mathrm{a}}$ & $4.922 \pm 0.078^{\mathrm{a} \mathrm{a} b}$ \\
\hline sRAGE $(\mathrm{pg} / \mathrm{ml})$ & $134.9 \pm 0.65$ & $245.5 \pm 1.15^{\mathrm{a}}$ & $284.9 \pm 0.90^{\mathrm{a}^{\mathrm{a}} \mathrm{b}}$ \\
\hline TAO $(\mathrm{mmol} / \mathrm{ml})$ & $6.45 \pm 0.041$ & $2.63 \pm 0.069^{\mathrm{a}}$ & $1.94 \pm 0.096^{\mathrm{a} b}$ \\
\hline
\end{tabular}

Data are expressed as mean $\pm S E, V E G F=v a s c u l a r$ endothelial growth factor, $A G E=$ advanced glycation end product, sRAGE=soluble form of receptor for advanced glycation end products, $T A O=$ total antioxidants.

$a: P<0.001$ as compared to the control group

$b: P<0.001$ as compared to the diabetic group

Table (3): Vitreous levels of different parameters in all studied group

\begin{tabular}{|l|l|l|l|}
\hline & Control & Diabetic & PDR \\
\hline VEGF (pg/ml) & $37.33 \pm 1.919$ & $82.47 \pm 5.788^{\mathrm{a}}$ & $1928 \pm 148.8^{\mathrm{a}^{\mathrm{a} b}}$ \\
\hline AGE $(\mathrm{unit} / \mathrm{ml})$ & $0.046 \pm 0.001$ & $0.134 \pm 0.001^{\mathrm{a}}$ & $0.167 \pm 0.002^{\mathrm{a}^{\mathrm{a}} \mathrm{b}}$ \\
\hline TAO $(\mathrm{mmol} / \mathrm{ml})$ & $1.816 \pm 0.014$ & $1.399 \pm 0.018^{\mathrm{a}}$ & $1.032 \pm 0.053^{\mathrm{a}^{\mathrm{a} b}}$ \\
\hline
\end{tabular}

Data are expressed as mean $\pm S E, V E G F=$ vascular endothelial growth factor, $A G E=$ advanced glycation end product, $T A O=$ total antioxidants, a: $P<0.001$ as compared to the control group, $b: P<0.001$ as compared to the diabetic group.

Table (4): Multiple correlations analysis between vitreous levels of different studied parameters in diabetic and PDR groups

\begin{tabular}{|c|c|c|c|c|}
\hline Parameters & $\begin{array}{l}\text { VEGF } \\
\text { Coefficient ( } \mathrm{r})\end{array}$ & $\mathrm{P}$ & $\begin{array}{l}\text { TAO } \\
\text { Coefficient ( r) }\end{array}$ & $\mathrm{P}$ \\
\hline $\mathrm{AGE}$ & 0.98 & $<0.0001^{* *}$ & -0.92 & $<0.001^{* * * *}$ \\
\hline TAO & -0.87 & $<0.0001^{* * *}$ & - & - \\
\hline
\end{tabular}

$V E G F=$ vascular endothelial growth factor, AGE=advanced glycation end product, $A O=$ total antioxidants 

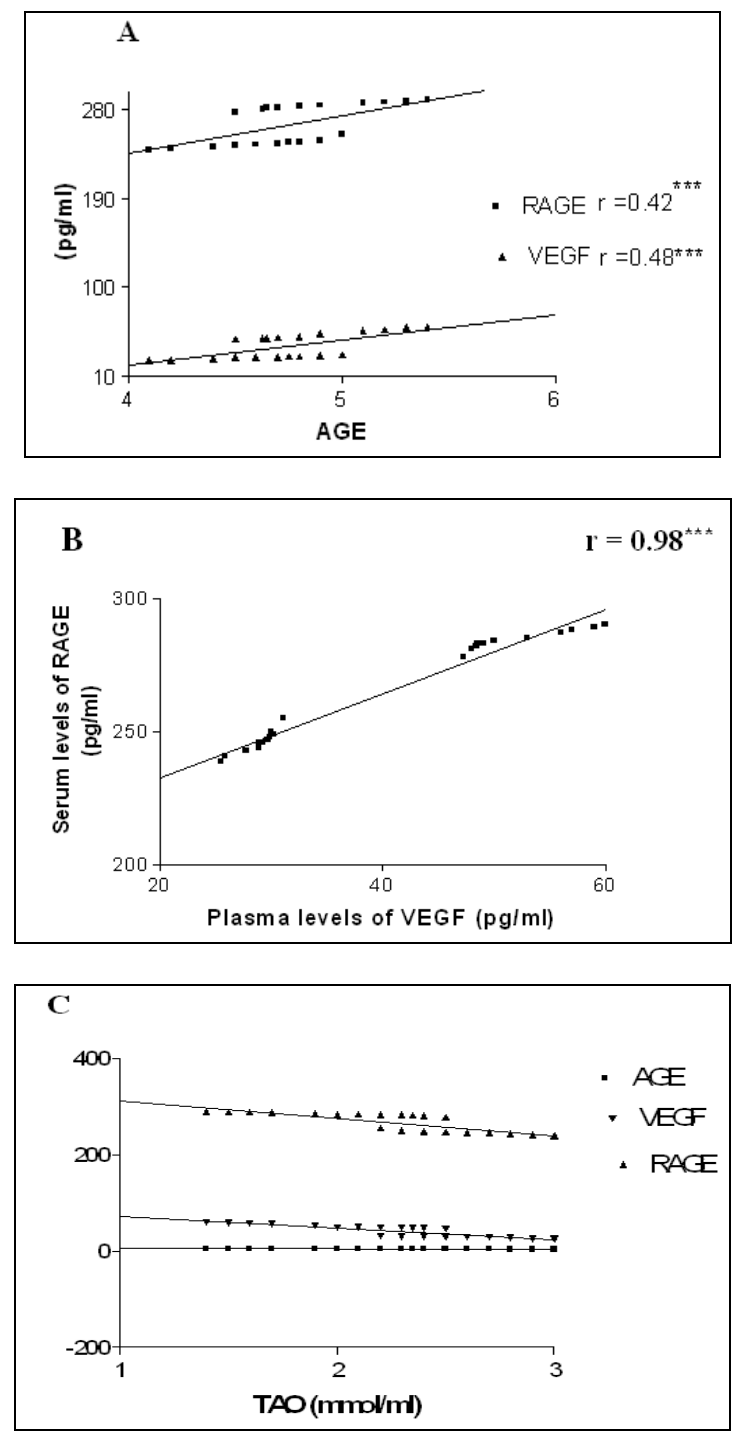

Figure (1): Multiple correlations analysis between blood levels of different studied parameters in all diabetic patients (diabetic and PDR) (A) Positive correlations between serum levels of AGE and blood levels of VEGF and sRAGE. (B) Positive correlations between plasma levels of VEGF and serum levels of sRAGE (C) Inverse correlations between serum levels of TAO and blood levels of AGE, VEGF and sRAGE, VEGF=vascular endothelial growth factor, $\mathrm{AGE}=$ advanced glycation end product, $\mathrm{TAO}=$ total antioxidants, $\mathrm{sRAGE}=$ soluble form of receptor for advanced glycation end products. $* * *=\mathrm{P}<0.001$ 


\section{DISCUSSION}

This study showed that the plasma VEGF and serum AGE levels in PDR group were significantly higher than those of diabetic and control groups, there was a positive significant correlation between VEGF and AGE in both PDR and diabetic group. This was explained by that chronic hyperglycemia favors glycation reactions and non enzymatic glycation. Reducing sugars can react non-enzymatically with amino groups of protein. These early glycation products undergo further complex reaction such as rearrangement, dehydration, and condensation to become irreversibly cross-linked, heterogeneous derivatives, which is AGEs. This leads to accumulation of AGEs in diabetes ${ }^{(\mathbf{1 9})}$ which can stimulate the expression of VEGF leading to increase its levels. This increase is also additive with hypoxia, another well-characterized stimulus for VEGF expression in diabetic retinopathy ${ }^{(20)}$.

Also sRAGE serum levels were significantly higher in PDR group than diabetic and control groups and were positively correlated with circulating AGE levels and VEGF in both diabetic and PDR group. This may be explained by that AGEs are positive regulators of cell expression of RAGE, and serum sRAGE levels are in humans. AGEs can stimulate RAGE through activation of nuclear factor- $\kappa \mathrm{B}$ in human vascular endothelial cells $^{(21)}$. Hence, in states of increased AGEs, RAGE expression is increased $^{(22)}$. The ability of AGEs to modulate RAGE expression is likely to contribute to the pathological state of chronic activation of full-length RAGE in diabetes. Hence, increased AGEs in the diabetic patients causes increased cell surface RAGE and through that leads to higher levels of sRAGE generated directly from this species. Circulating endogenous sRAGE which reflects tissue RAGE expression may increase as a countersystem against endothelial cells injury in diabetic patients ${ }^{(\mathbf{2 3})}$.

In the present study it was demonstrated that vitreous levels of both AGE and VEGF were significantly higher in PDR group than diabetic patients and control subjects, and their levels were elevated in association with the severity of neovascularisation in diabetic retinopathy. It was also found that vitreous levels of AGE and VEGF were positively correlated with each other. This is due to that AGE induces VEGF expression in retinal cell culture and animals ${ }^{(24)}$. Moreover, local accumulation of AGE could increase vascular permeability in diabetic macula via VEGF, thus being involved in the pathogenesis of PDR, in which vascular permeability is increased $^{(25)}$. AGE induces bloodretinal barrier dysfunction by stimulating retinal VEGF expression in rats ${ }^{(2)}$, which supports this speculation.

It was found that total antioxidant status was decreased in the serum and vitreous of PDR group than diabetic and control groups, and that serum and vitreous levels of AGE and VEGF were inversely correlated with the total antioxidant status in PDR and diabetic groups. These were explained 
by that formation and action of AGE not only induces oxidative stress by generating of reactive oxygen species via the AGE pathway leading to the activation of nuclear transcriptional factor, NF- $k \mathrm{~B}$, and causing further damage to the cells ${ }^{(\mathbf{1 8})}$, but also inactivate a superoxide scavenging enzyme, $\mathrm{Cu}-\mathrm{Zn}$ superoxide dismutase, both of which could lead to impairment of antioxidant defense systems. AGE may also contribute to the decreased total antioxidant status in diabetic retinopathy ${ }^{(\mathbf{2 6})}$.

Oxidative stress also has an effect in diabetic retinopathy: it regulates vascular inflammation, gene expression of growth factors and cytokines, such as $\operatorname{VEGF}^{(26)}$. Therefore, it is conceivable that the decreased antioxidant levels could further potentiate the deleterious effects of AGE on diabetic retinopathy through the overproduction of VEGF. Moreover, the formation, accumulation, and action of AGE are enhanced under oxidative stress conditions $^{(24)}$.

These observations suggest that AGE and oxidative stress generation form a positive feedback loop, thus has an important role in the development and progression of diabetic retinopathy ${ }^{(26)}$.

Total antioxidants status in the serum of PDR and diabetic group was inversely correlated to serum levels of sRAGE. It is conceivable that the decreased antioxidant levels could enhance the deleterious effects of AGE on diabetic retinopathy through the overproduction of sRAGE.

\section{Conclusion:}

This study suggests that AGE and oxidative stress generation play an important role in development and progression of proliferative diabetic retinopathy via induction of VEGF. So inhibition of AGE formation or oxidative stress generation could be a potential target for therapeutic intervention of diabetic retinopathy.

Also down-regulation of RAGE expression or blockade of the RAGE downstream signaling may be a promising target for therapeutic intervention in diabetic vascular complication.

\section{REFERENCES}

1. Bailey C.C., Sparrow J.M. and Grey R.H. (1999): The National Diabetic Retinopathy Laser Treatment Audit. III. Clinical outcomes. Eye, 13: 151-159.

2. Yamagishi, S., Takeuchi M. and Inagaki Y. (2003): Role of advanced glycation end products (AGEs) and their receptor (RAGE) in the pathogenesis of diabetic microangiopathy. Int. J. Clin. Pharm. Research, 23:127132.

3. Takeuchi M., Makita $\mathrm{Z}$ and Bucala R., (2000): Immunological evidence that non carboxymethyllysine advanced glycation end-products produced from short chain sugars and dicarbonyl compounds in vivo. Mol Med., 6:114-25.

4. Bucciarelli L.G., Wendt $T$ and Rong L. (2002): RAGE is a multiligand receptor of the immunoglobulin superfamily: implicationsfor homeostasis and chronic disease. Cell Mol Life Sci., 59:1117-1128. 
5. Bierhaus A., Humpert P.M. and Morcos M. (2005): Understanding RAGE, the receptor for advanced glycation end products. J Mol Med., 83:876-886.

6. Park IH, Yeon SI, Youn JH., (2004): Expression of a novel secreted splice variant of the receptor for advanced glycation end products (RAGE) in human brain astrocytes and peripheral blood mononuclear cells. Mol Immunol., 40:1203-1211.

7. Yonekura H., Yamamoto Y., Sakurai S., Watanabe T. and Yamamoto H. (2005): Roles of the receptor for advanced glycation end products in diabetes-induced vascular injury. J. Pharmacol. Sci., 97: 305-311.

8. Murata T., Khalil A., Hata Y., Yoshikawa $H$. and Inomata $H$. (1995): Vascular Endothelial Growth Factor plays a role in hyperpermeability of diabetic retinal vessels. Ophthalmic Res, 27:48-52.

9. Battegay E.J. (1995): Angiogenesis: mechanism insight, neovascular diseases, and therapeutic prospects. J Mol Med; $73: 333-46$.

10. Moss S.E., Klein $\mathbf{R}$ and Klein B.E.K. (1998): The 14- years incidences of visual loss in a diabetic population. Ophthalmology; 105: 998 - 1003.

11. Baynes J.W. (1991): Role of oxidative stress in development of complications in diabetes. Diabetes 40:405-411.

12. Armstrong D., Ueda T., Aljada A., Browne R., Fukuda S., Spengler R., Chou R., Hartnett
M., Buch P., Dandona P., Sasisekharan R. and Dorey C.K. (1998): Lipid hydro peroxide stimulates retinal neovascularization in rabbit retina through expression of tumor necrosis factor-alpha, vascular endothelial growth factor and platelet-derived growth factor. Angiogenesis, 2:93-104.

13. Feldman E. L. (2003): Oxidative stress and diabetic neuropathy: a new understanding of an old problem. Journal of Clinical Investigation, 111: 431-433, 2003.

14. Hinokio Y., Suzuki S., Hirai M., Suzuki C., Suzuki M. and Toyota T. (2002): Urinary excretion of 8-oxo-7, 8-dihydro2-deoxyguanosine as a predictor of the development of diabetic nephropathy," Diabetologia, 45:877-882.

15. Cai L. and Kang Y.J. (2001): Oxidative stress and diabetic cardiomyopathy:a brief review," Cardiovascular Toxicology, 1:181-193.

16. Kowluru R.A. (2003): Effect of reinstitution of good glycemic control on retinal oxidative stress and nitrative stress in diabetic rats. Diabetes, 52: 818-823.

17. Mohamed A.K., Bierhaus A., Schiekofer S., Tritschler H., Ziegler R. and Nawroth P.P. (1999): The role of oxidative stress and Experimental Diabetes Research NF- $\kappa$ B activation in late diabetic complications. BioFactors, 10:157-167.

18. Knapp G.R. and Miller M.C. (1992): Tests of statistical significance: Regression and 
Correlation. In: Clinical Epidemiology and Biostatistics $1^{\text {st }}$ Eddition. Williams and Wilkins, Baltimore, Maryland. PP: 255 274.

19. Lu M., Kuroki M., Amano S., Tolentino M., Keough K., Kim,K., Bucala R., and Adamis A.P. (1998): Advanced Glycation End Products Increase Retinal Vascular Endothelial Growth Factor Expression . J. Clin. Invest. $101: 1219-1224$.

20. Tanaka N, Yonekura H, Yamagishi S, Fujimori $\mathrm{H}$, Yamamoto $\mathbf{Y}$, Yamamoto $\mathbf{H}$ (2000): The receptor for advanced glycation end products is induced by the glycation products themselves and tumor necrosis factor-alpha through nuclear factor-kappa B, and by 17beta-estradiol through $\mathrm{Sp}-1$ in human vascular endothelial cells. J Biol Chem 275:25781-25790.

21. Forbes JM, Thorpe SR, Thallas-Bonke V. (2005): Modulation of soluble receptor for advanced glycation end products by angiotensinconverting enzyme-1 inhibition in diabetic nephropathy.J Am Soc Nephrol 16:2363-2372.

22. Pachydaki aS.I, Tari S.R. Lee S.E. Ma W., Tseng J.J., Sosunov A.A., Cataldergirmen G., Scarmeas N., Caspersen C.,
Chang S., Schiff W.,M., Schmidt W.N. and Barile G.R. (2006): Upregulation of RAGE and its ligands in proliferative retinal disease. Exp Eye Res., 82: 807-815.

23. Yamagishi S, Amano S, and Inagaki Y. (2002): Advanced glycation end products induced apoptosis and overexpression of vascular endothelial growth factor in bovine retinal pericytes. Biochem Biophys Res Commun; 290: 973-978.

24. Yokoi M, Yamagishi S., Takeuchi M, Ohgami K., Okamoto T., Saito W., Muramatsu M., Imaizumi T., and Ohno S. (2005): Elevations of AGE and vascular endothelial growth factor with decreased total antioxidant status in the vitreous fluid of diabetic patients with retinopathy, $\mathrm{Br} \mathrm{J}$ Ophthalmology ; 89:673-675.

25. Yamagishi, S., K. Nakamura, T. Matsui, Y. Noda, T. Imaizumi, (2008): Receptor for advanced glycation end products (RAGE): a novel therapeutic target for diabetic vascular complication Curr. Pharm. Des., 14:487-495.

26. Kowluru, R.A. and Kennedy A. (2001): Therapeutic potential of anti-oxidants and diabetic retinopathy. Expert Opin Invest Drugs, 10: 1665-1676. 


\section{دورالنواتج النهائية للتسكر و عامل النمو للطبقة المبطنة الوعائية فى اعتلال}

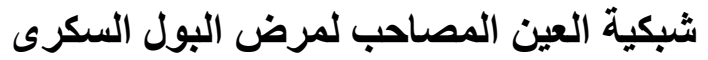

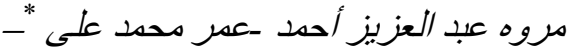

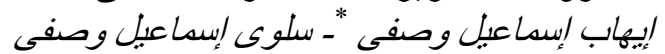

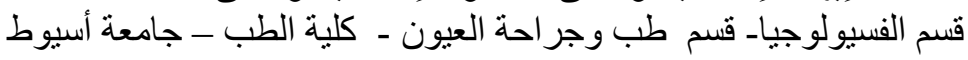

يعد مرض إعتلال شبكية العين المصاحب لمرض البول السكرى من الأمر اض الخطيرة التى تؤدى إلى

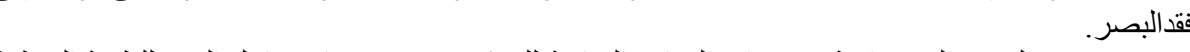

ويهذف البحث إلى دراسة مستويات النواتج النهائية للتسكر ومستقبلاتهاو عامل النمو للطبقة المبطنة

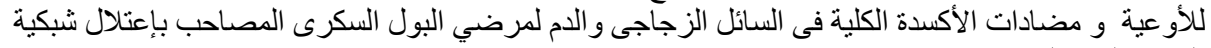

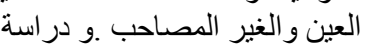
دور هم كمببات لمرض إعتلال شبكية العين المصاحب لمرض درض البول السكرى .

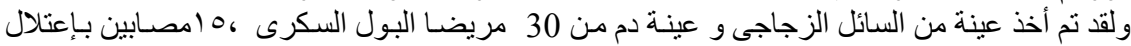

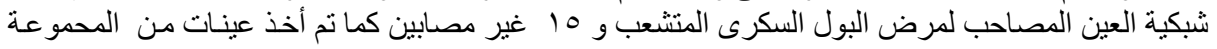

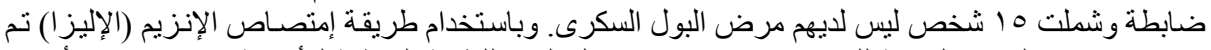

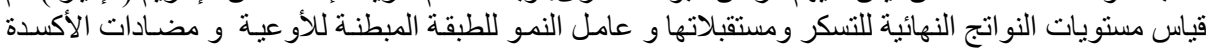

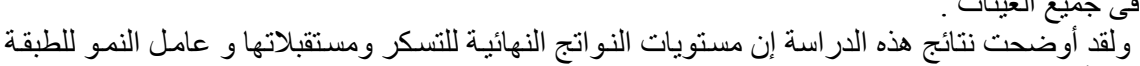

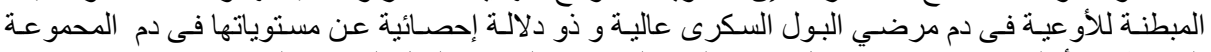

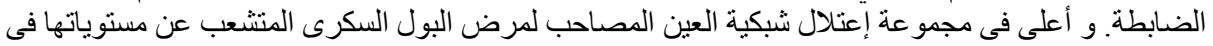

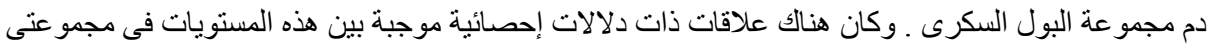

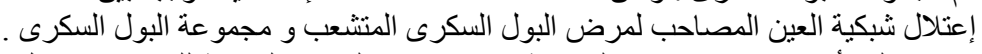

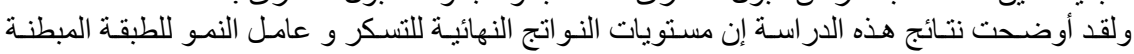

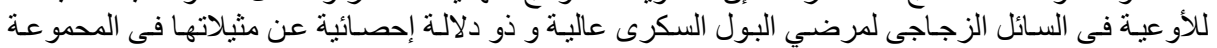

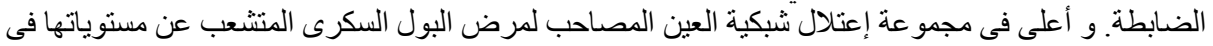

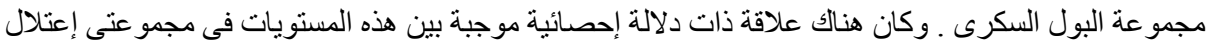

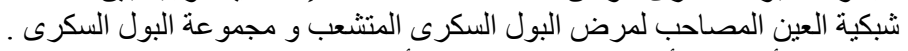

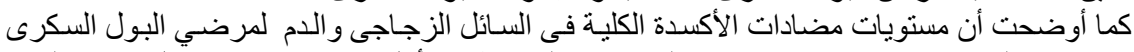

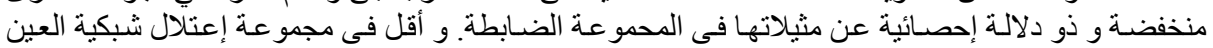

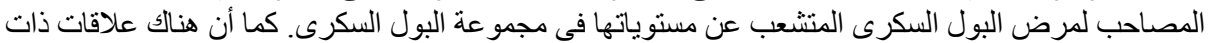

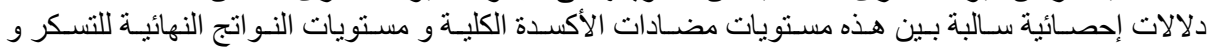

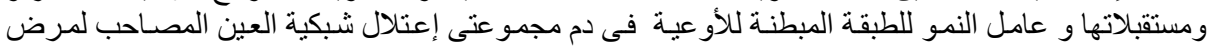

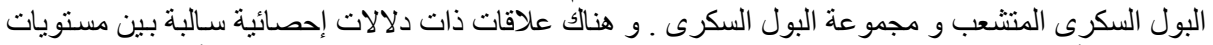

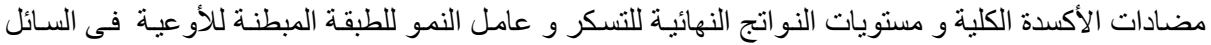

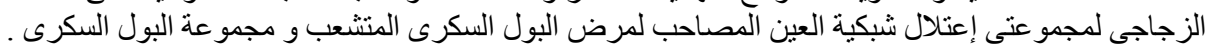

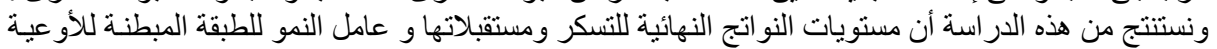

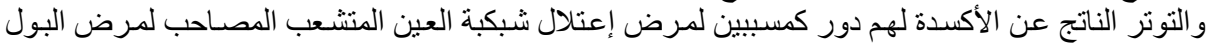

